\title{
Maori Models of Mental Wellness
}

The development a model of mental wellness, Te Ao Tūtahi that encompassed the complexity of Maori existence was initiated by the Māori forensic psychiatrist, Rees Tapsell. The objective of the proposed model was to depict the different cultural influences and experiences that have shaped Maori contemporary lifeways. It was envisaged that the model would help make sense of the cultural influences that contribute to Maori existence. The model was shaped by research into Tūhoe Kaumātua Mental Wellness undertaken in 2002 and was designed can be best described as an ontological model of mental wellness. The influence of Martin Heidegger (1962) is very obvious particularly his notion of worldviews in Being and Time. The different 'worlds' incorporated into the Te Ao Tūtahi model are:

Te Ao Whakanekeneke Māori world

Te Ao Pākehā - Pākehā world

Te Ao Hou Contemporary Maori world

Te Ao Tawhito Ancient Maori World

Therefore this model is not a kaupapa (framework) Māori model because it depicts external (non-Māori) ontological spheres of influence. The decision to deviate from a purely Maori ontological framework was influenced by the fact that the colonial experience impacts on every facet of Māori lifeways The model owes much to the Māori pioneers in the field, in particular, Te Rangimarie Pere (1982), Mason Durie and Te Kani Kingi (2000), and Graham Smith (1997).

From Te Ao Pākehā there is the obvious influence of Edward Said (1994) and Heidegger (1962) in shaping the model. The concept of ontological realities, the idea of different worldviews (embedded in distinctive cultural philosophical signification), owes much to the thought of Heidegger (ibid). His philosophy conveys the notion that the human experience is shaped by the forces of time, the past, the present, and a

Dr. Hinematau McNeill identifies primarily as Tapuika, and is a Principal Lecturer at Te Ara Poutama - AUT University's Faculty of Maori Development, and also works as a researcher. 
speculative future. This position is developed within an 'indigenous' paradigm when Edward Said (op.cit) contends that in the global context entwined histories and shared territories have produced an infinite variety of cultural configurations. In an earlier work, Orientalism (1979), Said introduces the idea of contestable territories, which raises issues surrounding domination and imperialism that also needed to be depicted in the model.

Therefore, the convergence of these somewhat disparate ideas provided the impetus for a Maori ontological model. Although other worlds that impinge on the Maori experience are intrinsic to the model, the locus is uniquely Maori. Ngamaru Raerino (personal communication, June 2004) named the model Te Ao Tütahi, which is virtually untranslatable yet denotes the idea of worlds standing side by side. The inter-relationships and interaction between the different worlds both negative and positive, is an integral aspect of the model. This idea will be explained in more detail in the full exegesis of the Te Ao Tütahi model. The exegesis concludes a critical analysis of the most widely accepted Maori models that have been developed and applied within the health and education fields. In this respect the Te Ao Tutahi model was developed in response to perceived methodological limitations with the existing Maori models: Te Rangimarie Pere's (1982) Te Wheke, Mason Durie's (1994), Te Whare Tapa Whā and his most recent addition Te Pae Mahutonga (1999). The focus of the critique is on methodological issues, which provides a point of reference to link these models to $\mathrm{Te} A o$ Tütahi is not intended to replace these models. Rather, its main function is as an additional analytical tool, to extend the research parameters and provide possibilities for further analysis.

All of the existing models embrace the Maori penchant for the poetic use of symbolic iconic Maori metaphors as a framework. The literal translation of Te Whare Tapa Whā is the four sides of the house. However, the concept of the whare (house) is laden with covert meaning. As already related in the previous chapter, whare tūpuna (ancestral houses) are symbolic personifications of tribal progenitors. The structural framework of the building depicts figurative parts of the body. For the most part the symbolism is generic, although there are minor tribal variations. For some tribes the porch represents the roro (brains), for others it is the facing wall that represents 
the brain. Durie (1994) has reworked and applied this concept to Te Whare Tapa Whā which represents four components of the total personality:

- Taha wairua (spiritual dimension)

- Taha hinengaro (mental dimension)

- Taha tinana (physical dimension)

- Taha whanau (social/family dimension)

Te Pae Mahutonga is the Maori name for the constellation of stars known as the Southern Cross. In Māori thought the night sky is an inextricable aspect of existence. The recent revival of Māori New Year celebrations in June is bringing ancient Māori customs into contemporary consciousness. Throughout Aotearoa the Māori New Year ushers in another cluster of stars known as Te Matariki (Pleiades). The star Puanga (Rigel) is also visible at around this time, and for some tribes Puanga rather than Matariki signifies the beginning of the New Year. Matariki is closely linked to horticulture, and connects to Papatuānuku (female earth deity). Te Pae Mahutonga is identified with Ranginui (male sky deity) and is associated with the ancient navigational systems of many cultures. Te Pae Mahutonga is of particular significance because it is linked to early voyaging traditions from Hawaiki to Aoteaora.

Te Pae Mahutonga is made up of six stars; four central stars and two pointers. The stars form a pattern of a cross, and on a clear night, are easily distinguished from the myriad of other celestial formations. Te Pae Mahutonga is symbolic of the four key requisites of health promotion and preservation.

The four central stars represent:

- Mauriora - access to Te Ao Māori

- Waiora - environmental protection

- Toiora - healthy lifestyles

- $T e$ Oranga - participation in society

The two pointers represent:

- $\quad$ Ngā Manukura (leadership)

- Te Mana Whakahaere (autonomy). 
The development of the health promotion model, Te Pae Mahutonga has more complexity both structurally and in the meaning of each of the component, than Te Whare Tapa Whä. Rather, Durie (1999) describes Te Pae Mahutonga as a model that is a symbolic map for bringing together the significant components of health promotion, as they apply to Maori health; and as they might also apply to other New Zealanders. In this sense both Te Pae Mahutonga and Te Wheke are universal models that contain strong Maori cultural influences.

In contrast Te Rangimarie Pere (1982) has created a model which is exclusively Maori. It also articulates the characteristic complexity of Maori philosophical thought. The literal translation of Te Wheke is the octopus. Although, not as familiar (symbolically) as the whare tupuna (ancestral house), the octopus has a special place in Maori consciousness. The main navigation tool for Maori has been the stars (cf. Te Pae Mahutonga). However, according to some traditions the octopus guided Kupe (the famous navigator) from Hawaiiki, the ancestral homeland of the Maori, to Aotearoa (Tetahi Roberts, personal communication, 1985). As a model of wellness Te Wheke utilises the parts of the octopus body to represent different structural components of the total personality within a socio-cultural framework. The head of the octopus represents the individual and the family unit from which eight tentacles radiate each symbolising different configurations of Maori being:

- Wairuatanga (spirituality)

- Mana ake (uniqueness of the individual)

- Mauri (ethos which sustains all life forms including the language)

- Hã a kui ma a koro ma (traditional cultural legacy)

- Taha tinana (physical aspect)

- Whānaungatanga (kinship)

- Whatumanawa (emotional aspect)

- Hinengaro (mind)

These components are self-explanatory and take into consideration human complexities symbolised by the suckers on each tentacle. These suckers represent the many facets contained within each of the configurations (of life). Whaiora (total wellbeing) is reflected in the eyes of the octopus. 
Interdependence of all parts of the model is a crucial factor, symbolised by intertwining tentacles. This interconnectedness of the different components is explicit in Te Wheke, whereas it is more implicit in the Te Whare Tapa Whā model.

The crucial difference between the various models is that 'Te Wheke' is an amplification of Māori concepts of being. The incorporation of the te ha (the breath of life) not only refers to physiological dependency on air to sustain life, but to Māori traditions pertaining to the origins of human existence. Central to this notion is tribal identity. The research into kaumātua wellness clearly emphasised the significance of Tūhoetanga (Tūhoe tribal affiliation) with emotional and spiritual wellbeing. In comparison Durie's (op.cit) emphasis is in accessibility to Te Ao Mãori (Māori world). He quite rightly contends that the realities of modern Māori existence exclude the majority of Māori (from access to the Māori world). In Te Pae Mahutonga Durie advocates redressing Māori cultural deprivation through accessibility to a range of different Māori cultural experiences. These include marae and other distinctively Māori social contexts. However, this notion of accessibility must take into account Māori spirituality. It is possible that despite the best intentions, the provision of Māori cultural experiences has the potential to cause mental unwellness.

The concept of mate Maori invariably related to the consequences of transgressing tapu (Māori laws/sanctions). Visits to marae and other tribal areas that are designated tapu, become extremely tapu during pōhiri (ceremonial welcome) and need to be carefully managed. Many modern Māori are unaware that the rituals involve the invocation of the dead. The purpose of the rituals is essentially to protect the living. Both the tangatawhenua (hosts) and the manuhiri (visitors) bring the past to the encounter. The ancestors of both are carried on their shoulders. Any animosities or conflicts that occurred between the ancestors are remembered, and placated through the proper observance of the rituals. Most Māori raised in rural communities are familiar with Māori customs and practices, even if they are uninformed of the reasons for behaving in particular ways. This provides them with cultural security that Māori raised away from their tribal areas do not possess. Accessibility to Māori cultural experiences may be critical to cultural identity, but in order to ensure positive outcomes this assess must take into 
consideration the complexities of the experience and therefore must be carefully managed.

It is clear that the Te Wheke model does not take into consideration Māori cultural deprivation because the primary objective of the model is the articulation of a tüturu Māori or traditional Māori beliefs. The emphasis of the Te Wheke model is on the uniqueness of Māori philosophical beliefs and values. Te hā a kui ma a koro ma (traditional cultural legacy) specifies the inheritance of the Māori cultural past from the ancestors. Te Rangimarie Pere (op.cit) is resolute that the restoration of Māori wellness is absolutely contingent on tūturu Māori learning. The setting for the model was based on the life experiences of $\mathrm{Te}$ Rangimarie Pere who grew up in Waikaremoana immersed in the language and traditions of a small Māori rural community. Although the model is acclaimed in other tribal areas, it is understandably imbued with cultural perceptions unique to the people of Tūhoe.

Although it can be argued that each tribe have their own concept of health and wellness, Mason Durie's (op.cit) Te Whare Tapa Whā model is representative of most cross tribal models because it depicts the basic components of a holistic concept of health. This is supported by the research, whereby Tūhoe kaumätua described a model of wellness identifying the elements included in Te Whare Tapa Whă. This was a surprising outcome considering the Te Wheke model of health was developed by Te Rangimarie Pere who is tūturu Tūhoe.

As already alluded to the main problem with the 'Te Wheke' model is that it is difficult to apply, which may account for a preference toward the simplicity of Te Whare Tapa Whā. An example of the difficulty in adapting the Te Wheke model in a modern context occurred at The Waiariki Polytechnic, which adopted 'Te Wheke' as a framework for the Health Studies curriculum for nursing. In the process the most culturally significant tentacles, Te Mauri (life force) and Te hã a kui ma a koro ma were amputated, simply because they could not fit into the nursing curriculum. While this resulted in its transformation into a model that could be adapted crossculturally, the reconstituted model lost its most important asset, mātauranga Māori (Māori epistemology). The problem was further exacerbated by the absence of a Maori language component being integrated into the programme. The reality is that in the period from 1987 to 1990 there was only one native Māori speaking student enrolled and none of the lecturers 
were competent Māori speakers. Ngamaru Raerino (private communication, 17 September 2003) insists that Mātauranga Māori is critical to any Māori wellness model and that Māori concepts of health should provide the standard against which intervention plans should be measured.

In contrast Mason Durie (1994) described his model Te Whare Tapa Whà as '...simple even simplistic but that was also its appeal' (p74). The comparative simplicity of the Te Whare Tapa Wha may explain its universal application within the health field in Aotearoa. Kaumātua responses reinforce and support this view, demonstrating that the simplicity of the 'Te Whare Tapa Wha' model made it a convenient point of reference. The problem with the 'Whare Tapa Wha' model is that it does not define the uniqueness of Māori as a cultural entity. The Māori translations should carry mātauranga Māori messages that defines and distinguishes the four components of health as uniquely Māori? 'Te Whare Tapa Whà' reflects in essence a holistic perception of health that is more generic in that could easily be translated and applied to any crosscultural analysis of wellbeing.

What exactly distinguishes the taha hinengaro (mental dimension) from a Pakeha mental dimension, an Indian mental dimension or any other culture's conceptualisation of the mental dimension? Similarly, what exactly distinguishes the taha tinana (physical dimension) from a Pakeha physical dimension, an Indian physical dimension or any other culture's conceptualisation of the physical dimension? These questions can also be applied to the Te Pae Mahutonga model because this model also contrives to be all-inclusive. However, Te Pae Mahutonga does incorporate the socio-cultural outcomes of the colonial experience into the model. Furthermore, strategies to redress the detrimental effects of colonisation are articulated in relation to the various components of the model.

Durie (op.cit) does acknowledge colonisation as a driving force in the explication of the Te Whare Tapa Wha model, but this remains covert. The 'Whare Tapa Wha' model is essentially a personality profile that does not take into account other variables that have a significant impact on the health status of an individual. A continuing theme throughout this research project is the idea that Māori cultural concepts no longer exist, separate from the political and social ramifications of colonial history. It is virtually impossible to 
address the reality of the contemporary experience on Māori without taking cognisance of colonisation as a key factor in shaping the destiny of Māori. It can be argued that the problems associated with poverty, that many rural MĀori confront, are compounded within Tūhoe because of the geographical isolation of much of the area. This impacts on the general health of the population in terms of employment opportunities, access to essential services, and the higher cost of basic necessities. The contention that kaumatua unwellness is caused by socio-economic determinants beyond their control, was covered in the previous chapter.

It has already been argued in the literature search that the influence of Pākehā beliefs and values on rural marae centred communities, generally appeared to be peripheral. The impression in these communities is that a distinctive Māori culture continues to exist, regardless of Pākehā influences. The supposition is that the syncretism of 'traditional' values and beliefs and Pākehā adaptations has given rise to a uniquely contemporary Māori worldview; Te Ao Hou (the New World) is a syncretism of traditional Māori and European cultural constructs. It is interesting to note that Te Ao Hou is perceived to belong exclusively to the Māori cultural domain because European influences are subjugated, and concepts are articulated in the Māori language. Certainly, there is little deference to European origins.

However, kaumatua responses in the research provided evidence that suggested the appropriation of Māori beliefs in some areas. A small minority indicated that their religious practices were situated solely within the Christian faith. Although they attended rituals that were tüturu Maori (traditional) their personal faith was resolutely Christian. It was determined from their responses that maintaining a sense of wellbeing was determined more by their Christian faith than tūturu Maori beliefs and practices. This is evidenced by the following responses to the survey question:

\section{Question: He aha ki a koe te oranga tangata?}

What is your understanding of wellness?

\section{R: Karekau he maharahara ki tetahi atu mea kei a ia te oranga tangata wairua}

I do not think much about this - The spiritual wellbeing of the people is with him. 


\section{R: Ko te whakapono ki te Atua Belief in God.}

\section{R: Whakaaro ki te runga rawa}

Thoughts towards God.

It could also be argued that the propensity for Māori to move with ease between different belief systems raises some question about the assumption that Christianity dominates their sense of wairuatanga (spirituality). In the biography 'Tohunga' Hohepa Kereopa refers to the 'Almighty' in relation to a miraculous experience:

'This was an important lesson for me to learn,' Hohepa noted. 'It taught me about the total power of the Almighty...'

(Moon, 2003 p.53).

The unconscious shift from one ontological belief system is not just the prerogative of tohunga (Maori priest/specialist), and is an observable characteristic of Māori cultural behaviour. In terms of analysis this blurring of beliefs and practices presents difficulties. Te Ao Tütahi was developed as an outcome of the research into Tūhoe kaumātua wellness. Its main feature is that it separates the different beliefs and practices, and thereby facilitates an unambiguous understanding of the issues.

This complication is explored in the relation to 'Hui Oranga' A Mãori measure of a mental health outcome (Durie \& Kingi, 2000). The process of evaluation relied on the application of Te Whare Tapa Whā as a cultural measure of a mental health outcome.

The tool is designed to be a quick, easily administrated measure of outcome, appropriate for routine clinical use. It may be used as a specific cultural measure of outcome or combined with other, more targeted clinical tools. Application should take no longer than $10-15$ minutes (p.2).

The process relies on perceptions of well being to gauge gains in mental, physical, spiritual and social health. The process involves interviewing the clinician, patient and patient's whanau for their personal opinions on the outcomes of the patient's care/treatment plan.

A treatment plan may, for example, include interventions or processes designed to enhance a dimension of health, which is culturally founded, such as wairua. A service may do so in a variety of ways and could include karakia or powhiri as part of a spiritual intervention. The outcome of this particular process 
might be significant and important part of the client's treatment and recovery plan. Measures of outcome which neither consider the intervention or the outcome are likely to disadvantage services which operate within that type of cultural paradigm (ibid, 2000, p29).

However, the report does not provide sufficient evidence of the Maori 'standards' it purports to measure. The outcomes of interventions do not appear to relate to mātauranga Māori to measure Māori standards of healing. Apart from one question relating to the strengthening of the client's Māori identity, the assessment tool is devoid of any explicit Māori subject matter. If the assessment strategy included an intervention programme designed around a kaupapa Māori framework the tool would have the potential to contribute enormously to the advancement of the Māori health status. Cultural components are not integrated into intervention programmes simply because they are included in the methodology. Measuring mental health outcomes requires that the assessment defer to Māori conceptualisations. However, the impact of colonial experience on Māori life ways is an important consideration. It is possible to integrate this into the evaluation process as the following analysis demonstrates.

It has been established that the use of karakia (prayers/incantations) may be included 'as part of a spiritual intervention' strategy. But omitted from the description of the planned intervention is important contextual information, such as the type of karakia. Was the karakia an ordinary Christian prayer, recited in English? A Christian karakia recited in Māori, or a pre-European contact karakia invoking the traditional Māori atua (gods)? The cataloguing of the different origins of prayers also provides a more definitive representation of present day Māori life ways, where Māori are subject to different cultural influences. Separating the cultural configurations of the different interventions would facilitate the analysis. These components differentiate Māori wellness strategies and could even test the efficacy of different types of Māori spiritual ritual practices In fairness to Durie and Kingi (ibid) their work does not claim to be the definitive example of evaluation, and have identified the necessity of further developments in Māori measurement standards. The contention here is that the publication of the 2000 report indicated that a Mãori measurement of health was being implemented in a clinical setting. 
While Māori will benefit from the measures which consider clinical aspects of the outcome, culturally founded outcome preferences will likewise need to be explored so that a more complete assessment of outcome, aligned to Maori concepts of health, can be determined (p27).

The potentiality for integrating tūturu Maori (traditional/authentic) into clinical practices is far reaching. It is widely acknowledged that mate Māori - Maori sickness that some 'mental afflictions' are beyond the scope of conventional intervention methods. According to Hohepa Kereopa (personal communication, 2004) the faith or the belief of the individual is the most significant factor in healing. This notion is captured in the following incident involving a whanau member who had burnt herself cooking panekeke (pancakes) at a hui in Te Puke.

The burn had already started to blister and there was a frantic rush as family prepared to take her to the Hospital Outpatients. On the way out Hohepa was spotted in the wharekai (dining room). He merely looked intently at the hand for about thirty seconds, and then told her that she would be all right. The subsequent healing process can be described as comparable to the rewinding of a video recording in slow motion. Over a period of approximately half an hour or so, the burn actually receded, leaving no visible mark whatsoever. The healing procedure involved no conspicuous displays or ritual commonly associated with the tüturu Maori practices of the tohunga. What is interesting in this case is that the 'patient' is a medical doctor and the healer a tohunga. Obviously in this instance their professional roles embraced a synergy of science and spiritual beliefs. The patient had absolute faith in Hohepa's skill as a tohunga, although she was not expecting any miracles. Hohepa too will defer to science by consulting medical professionals and medication for his own ailments, provided he considers this the most appropriate form of treatment.

Therefore, the whole issue of Māori healing is convoluted and complex and the use of Māori cultural interventions in the mental health field require more comprehensive examination. Notwithstanding the apparent difficulties inherent in the development of a Māori measurement 'aligned to Māori concepts of health', it is an exciting prospect. It should also be noted that Māori endeavours to apply Māori models are often met with resistance, rather than enthusiasm in mainstream institutions. Māori advancement in both the education and 
health fields owes much to the innovative thinking of Māori theorists and to Māori professionals who have challenged the status quo; and have been forced to make compromises. This is the reality of Māori existence in a neo-colonial environment. While acknowledging the challenges Mason Durie has endured to advance Māori in the health field, the absence of a Māori epistemological basis to his model of wellness is needed.

Although both the Te Whare Tapa Wha and the Te Wheke models approach to health is holistic, it is devoid of tüturu Māori knowledge systems that distinguish it clearly from any other wellness model. When the Te Whare Tapa Wha is compared with the World Health Organisation's (WHO) definitions of health the WHO primary health care statement from (1978) states:

The conference strongly affirms that health, which is a state of complete, physical, mental and social wellbeing and not merely the absence of disease or infirmity... (p2).

The exception in the Te Whare Tapa Whā is that it includes a spiritual dimension, which is conspicuous by its absence in the WHO model. It has already been established that, taking into account equilibrium in relation to all components, the 'taha wairua' (spiritual component) is the cornerstone of Māori concepts of health. Similarly, as Durie concedes the Te Pae Mahutonga model is inspired as much by the Ottawa Charter (1986) as it is by Maori conceptualisations.

Good health is a major resource for social, economic and personal development and an important dimension of quality of life. Political, economic, social, cultural, environmental, behavioural and biological factors can all favour health or be harmful to it. Health promotion action aims at making these conditions favourable through advocacy for health (pg 1).

Again, the spiritual dimension is conspicuously absent from the WHO health promotion model. Perhaps it is this preoccupation with the spiritual that differentiates 'western' from 'indigenous' worldviews. While researching Māori conceptualisations of health, Mason Durie observed kaumātua attention to the paramountcy of the spiritual in Māori thought.

During the welcome kaumatua Tupana Te Hira had emphasised in Maori the importance of wairua as a starting point for health. It was a view that many kaumatua shared and was frequently heard on marae throughout the country (p.70).

Notwithstanding the omission of the spiritual dimension, the WHO in collusion with most holistic health models, defines 
good health as an optimum state of wellness. According to this paradigm, wellness occurs when all the different aspects of the healthy personality: physical, mental, social, and spiritual, are in harmony and are fully functional. This demonstrates that an optimum standard of wellness, indicating wellness in all aspects of the personality, is the ideal. This concept of health is problematic for two reasons. Firstly, kaumatua definitions of wellness (tüpakari) include those who have an obvious disability. In actuality, as the majority of Tūhoe kaumātua suffered from a range of physical illnesses. This did not appear to affect their mental wellness. However, in terms of a holistic approach to wellness their physical health status affected their overall wellness status, depending on the degree of affliction. In this context it is important that perceptions of health and their enviable health status should not be construed as total wellness. The point being clarified here is that a holistic concept of health does not necessarily mean that an individual has to be in an optimum state of health. It must be recognised that Tūhoe kaumātua have issues relating to poverty and problems of physical un-wellness that need to be urgently addressed, in spite of the perceptions they hold regarding their own well-being.

Secondly and perhaps more critically, confusing health with illness creates unnecessary complications, especially in terms of implementing intervention strategies. Rees Tapsell (private communication July 17, 2003) also supported the notion that mental wellness is a separate entity, irrespective of the cultural frameworks. He criticised the conventional use of health, as a single construct to include all states of mental illness as well as mental wellness. The application of a wellness model to measure the effectiveness of intervention strategies to individuals experiencing mental problems suggests that wellness and un-wellness exist on a continuum, rather than as dialectically opposed, separate entities. The research findings (which went beyond the actual surveys) on defining wellness, signalled that in Maori conceptualisations, wellness exists as an entity separate from un-wellness.

To support this argument kaumātua who participated in the research did make a clear distinction between wellness and un-wellness. Similarly, their responses indicated perceptions of different states or experiences of wellness. This generally held perception advocates a paradigm that is essentially characterized as a single continuum from extreme illness to optimum wellness. This is contradictory because the 
word 'health' signifies wellness. Maori conceptualisations distinguish wellness and un-wellness very clearly: oranga (wellness), and matenga/mauiuitanga (un-wellness). The word used to describe health is 'oranga' which derives from 'ora,' which means to be alive and/or well. Conversely mate can signify illness or death depending on the context. It was apparent from kaumātua responses that the dialectical positioning of wellness as opposed to unwellness did not preclude the idea of different states of wellness and unwellness.

The definition of wellness and unwellness is integral to the planning and implementation of community health care. This wellness strategy is contained in Clause 4 of the WHO, Alma Ata (op.cit), suggests that the planning and implementation of health care is a basic human right.

The people have the right and duty to participate individually and collectively in the planning and implementation of their health care (ibid).

What is not explicated is the right of individuals and communities to 'define' health care, and implicit in clause 4 is the tacit acceptance that health care is a universal construct. It would have been more meaningful if the WHO statement on health emphasised the right of different cultures and communities to define their own notions of health. There may not be a definitive outcome, but each culture has the right to devise paradigms that are relevant to their own unique cultural experience. These ambiguities suggest that defining wellness or health is difficult, which impacts on intervention strategies.

Maori felt that their relationship with health professionals and the health system generally had become strained. Rightly or wrongly a feeling of alienation had arisen, not necessarily because of poor access or inadequate care, but mainly because there was a lack of shared decision making and a limited recognition of Maori view. Maori health perspectives such as whare tapa wha were welcomed because they provided the necessary framework within which a semblance of ownership over health could be entertained (op.cit, 1977, p. 75).

It can be safely deduced that care plans that derive from models shaped and endorsed by consumers, is preferable to one that is imposed. The WHO definition of health, while motivated with good intentions, perpetuates a paternalistic paradigm. The 'power to define' and the subsequent intervention strategies require a less paternalistic approach, 
with more confidence in the ability of previously colonised or marginalised people to determine their own health paradigms and health needs.

The Te Wheke model reflects a tūturu Māori representation but ignores (perhaps deliberately) the realities of contemporary Māori existence, and the impact of colonisation on the Māori psyche. The challenge was to construct a model that retains the simplicity of Te Whare Tapa Whā, without compromising the cultural integrity of Māori conceptualisations contained in Te Wheke. Consequently the Te Ao Tütahi model attempts to provide the means to integrate all the diverging methodological models into a single cohesive tool of analysis. This task was undertaken with the realisation that Māori cultural concepts are complex, and furthermore that most needed to be contextualised or framed within the specific intervention process to be fully appreciated. The strength of the Te Ao Tütahi model is that it recognises that Māori are subject to a complexity of cultural influences.

The Te Ao Tütahi model separates different ontological realities and effectively demarcates specific areas of beliefs and practices. The model provides a means or method for effective epistemological analysis because it deconstructs the different cultural spheres or realities. From this perspective the Te Ao Tūtahi model is primarily a methodological tool to analyse Māori reality or realities:

- Te Ao Whakanekeneke (Global world)

- Te Ao Pākehā (European world)

- Te Ao Hou (Synthesis of cultural elements from Māori and Pākehā worlds)

- Te Ao Tawhito (Māori world -origins in pre-contact Maori existence) 
Figure 1: Te Ao Tūtahi - Adjacent Worlds

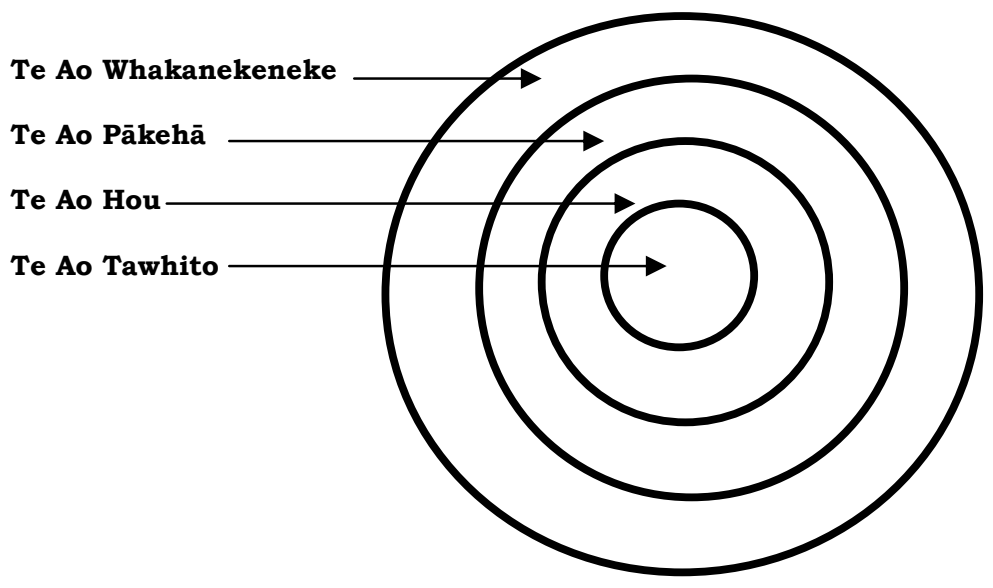

When applied to the research environment, data can invariably be differentiated according to the influence of specific world-view components. The model also assists where a more complex approach is required in the analysis of other questions. Pākehā cultural influences were apparent in some responses that were considered essentially Māori, and this presented a methodological challenge. A model was required that separated tūturu Māori (pre-contact Maori ideological beliefs and practices) and contemporary Māori ideological beliefs and practices; that clearly demarcates the different influences on contemporary Māori beliefs and practices. This alternative model simply aligns the different worlds in which Māori interact. Essentially the Te Ao Tütahi model provides a paradigm of Māori mental wellness that takes into consideration, different cultural influences on Māori, while at the same time retaining deference to traditional Māori thought demonstrated by the placement of Te Ao Tawhito in the central position. The arrows on the following diagram depict the movement between each of the different world creating cultural configurations and influences - both positive and negative. 
Figure 2: Te Ao Tūtahi - Adjacent Worlds (Interactive)

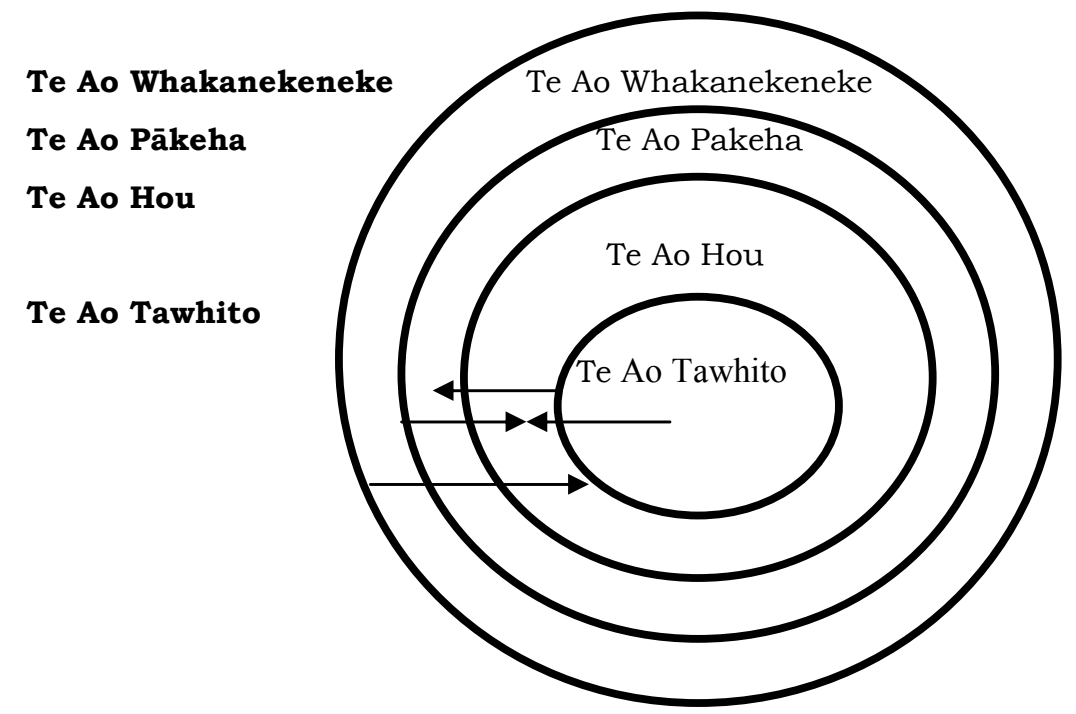

It has already been stressed that many Māori move effortlessly between different worldviews or realities. Although the transition between the different worlds is seamless in ordinary existence, for analytical purposes it is useful to separate them into different entities. The functioning of this model is best demonstrated in the context of a real life case study, reflecting ordinary everyday activities. This observation occurred in March 2002. Hohepa Kereopa in his role as a tohunga was asked to lift the tapu (in this context malignant spiritual influence) from a Whakatane building. On the way to perform the ceremony he stopped at the bank to withdraw money. When he arrived at the building in question, he exchanged pleasantries with the Pākehā manager and other participants from the organisation. The ceremony began with a himene Māori, a Christian hymn that is sung in Māori. Hohepa began the cleansing ceremony with a karakia Ringatū that has origins in both Maori traditional beliefs and Christianity. As he moved around the building he began to recite karakia that pre-dates Christianity. When the ceremony was completed 
Hohepa returned home and logged onto the Internet. Within the space of approximately six hours Hohepa had traversed all four planes of reality as depicted in the following table.

Figure $3 \quad$ Case Study

\begin{tabular}{|l|l|}
\hline Ontology & Activity - select examples \\
\hline Te Ao Pākehā & Use of bank facility \\
\hline Te Ao Hou & $\begin{array}{l}\text { Hymns, prayers and other rituals that } \\
\text { contain Christian and Māori elements } \\
\text { performed in the Māori language. }\end{array}$ \\
\hline Te Ao Tawhito & $\begin{array}{l}\text { Invoking Māori deities through the } \\
\text { recital of ancient prayers and ritual. } \\
\text { Māori language including ancient words } \\
\text { that have lost meaning in the } \\
\text { contemporary world. }\end{array}$ \\
\hline $\begin{array}{l}\text { Te Ao } \\
\text { Whakanekeneke }\end{array}$ & Use of the world wide web \\
\hline
\end{tabular}

Peter Harwood (personal communication, 26 January 2005) commented that the global world and the Pākehā world were virtually the same. However, he acknowledged that the demarcation of the Pākehā world was critical to Māori conceptualisations of existence. Although it is conceded that Pākehā culture is essentially a global western culture. The retention of Te Ao Pākehā within the Te Ao Tutahi model is critical because Maori perceive the Pākehā world as an entity separate from the rest of the west.

In conclusion, Te Ao Tütahi presents a Māori paradigm that encompasses all Māori irrespective of their life experiences. For example, there are those Māori who by choice or circumstance, interact totally within the confines of Te Ao Pākehā. The only discernible difference between this person and any non-Māori is ethnicity. But by virtue of 
whakapapa every person who has Māori blood has a legacy implanted in Te Ao Tawhito). Whakapapa is the key to membership. The following whakatauki (proverb) recognises these ancient bloodlines:

\section{E kore au e ngaro te kākano i ruia mai $i$ Rangiatea}

The seed sown in Rangiatea, you will never be lost

The issue of 'Māoriness' or identity is especially poignant for urban Māori, many being estranged from their tribal roots. The mental wellness paradigm recognises this phenomenon. It is likely that the majority of Māori requiring mental health intervention are alienated from their tribal roots. Certainly the research undertaken amongst the Tūhoe kaumātua provides a reasonable basis for this kind of speculation. The research indicates that Māori who are comfortable in the Māori worlds (Te Ao Tawhito and Te Ao Hou) are more likely to be mentally well. This supposition is founded on the basis that the survey showed an apparent absence of mental health problems amongst an aging Tūhoe population. When other cultural influences impinge on an exclusive Māori world view, the Te Ao Tütahi model becomes most useful. The defining of the different and very separate entities simplifies the methodological approaches as applied to this research project. As already discussed in relation to mental health intervention strategies, Te Ao Tütahi can be seen as an additional resource to extrapolate and identify the origin of different intervention processes. Furthermore, the model can be applied to a range of different contexts and for different purposes, although it was designed originally to assist with the analysis of Māori mental wellness.

\section{Bibliography}

Durie, M. (1994). Whaiora, Maori Health Development. Auckland: Oxford University Press.

Durie, M. (1999). Te Pae Mahutonga: A Model for Maori Health Promotion. In Health Promotion Forum of New Zealand Newsletter 49, 2-5 December 
Heidegger, M. (1962). Being and Time. San Francisco: Harper.

Kingi Te K.R. \& Durie, M. H. (2000). Hui Oranga, a Maori Measure of Mental Health Outcome. A Report Prepared for the Ministry of Health, Massey University, Palmerston North.

McNeill, H. (2005). Te Hau Ora o Ngā Kaumātua o Tūhoe - A Study of Tūhoe Kaumātua Mental Wellness. Doctoral thesis, AUT University.

Moon, P. (2003). Tohunga Hohepa Kereopa. Auckland: David Ling Publishing.

Pere, R. (1982). Ako Concepts, Learning in the Maori tradition. Hamilton: University of Waikato Press.

Said, E. (1979). Orientalism, Western Conceptions of the Orient. New York: Vintage.

Said, E. (1994). Culture and Imperialism. New York: Vintage.

Smith, G. (1997). The Development of Kaupapa Maori: Theory and Praxis. Doctoral thesis, University of Auckland.

World Health Organisation. (1978). The WHO Primary Heath Care Statement. Conference at Alma-Ata. 